\title{
Bilateral Chylothorax: A Rare Complication following Radical Neck Dissection
}

Neil Scott ${ }^{*}$, Isaac R, Mustafa S and Kittur MA

Department of Oral and Maxillofacial Surgery, Morriston Hospital, Swansea, Wales. SA6 6NL, UK

*Corresponding author: Neil Scott, Department of Oral and Maxillofacial Surgery, Morriston Hospital, Swansea, Wales. SA6 6NL, UK, Tel: 07968612303; E-mail: neil.scott@icloud.com

Rec date: May 19, 2015; Acc date: Jul 23, 2015; Pub date: Jul 25, 2015

Copyright: (C) 2015 Scott N, et al. This is an open-access article distributed under the terms of the Creative Commons Attribution License, which permits unrestricted use, distribution, and reproduction in any medium, provided the original author and source are credited.

\section{Abstract}

Bilateral chylothorax as a complication of neck dissection is very rare with only 29 cases reported in the English literature. We present our case and review the anatomy, pathophysiology, clinical features and management.

Keywords Chyle; Bilateral chlyothorax; Neck dissection

\section{Introduction}

The risk of a chyle leak following on from a neck dissection is approximately $1-2 \%$ [1]. The risk of a chylothorax is much lower, such that there are only 29 cases of bilateral chylothorax after neck dissection reported in the English literature (PubMed) since 1951. Despite its rarity, it is imperative that the clinician holds a high index of suspicion in the dyspnoeic post-operative neck dissection patient in order to implement early intervention. Failure to do so may result in serious respiratory, cardiac, metabolic and immunologic derangement.

\section{Case Report}

A 74-year-old gentleman with metastatic SCC underwent a left sided selective neck dissection incorporating levels $1-4$, with no intraoperative complications.

Post-operatively (day 6) the patient developed dyspnoea. Clinical examination revealed minimal air entry bilaterally, with arterial blood sampling showing type I respiratory failure. The clinical suspicion was a pulmonary embolus, however, a chest radiograph showed bilateral pleural effusions (Figure 1). The patient underwent ultrasound guided pleural aspiration and $100 \mathrm{ml}$ of turbid fluid drained from each lung. The biochemical assay of the pleural aspirate confirmed the diagnosis of bilateral chylothorax. The patient was commenced a low fat, medium chain fatty acid diet. Subsequently, the dyspnoea settled and a repeat chest radiograph on post-operative day 14 confirmed resolution of the chylothorax.

\section{Discussion}

\section{Chyle and its composition}

The word chyle comes from the Latin chylus, which means juice. It is an alkaline mixture of intestinal lymph and emulsified fats, with a milky appearance. The composition of chyle varies according to an individual diet but it is essentially composed of protein and fat. The volume of chyle produced each day is approximately 3-5 litres with flow increasing during the absorption phase of digestion and decreasing during fasting. Brennan et al. [2] highlighted that this decrease in flow during fasting may make the identification of chyle during intra-operative damage to the thoracic duct even more challenging [2].

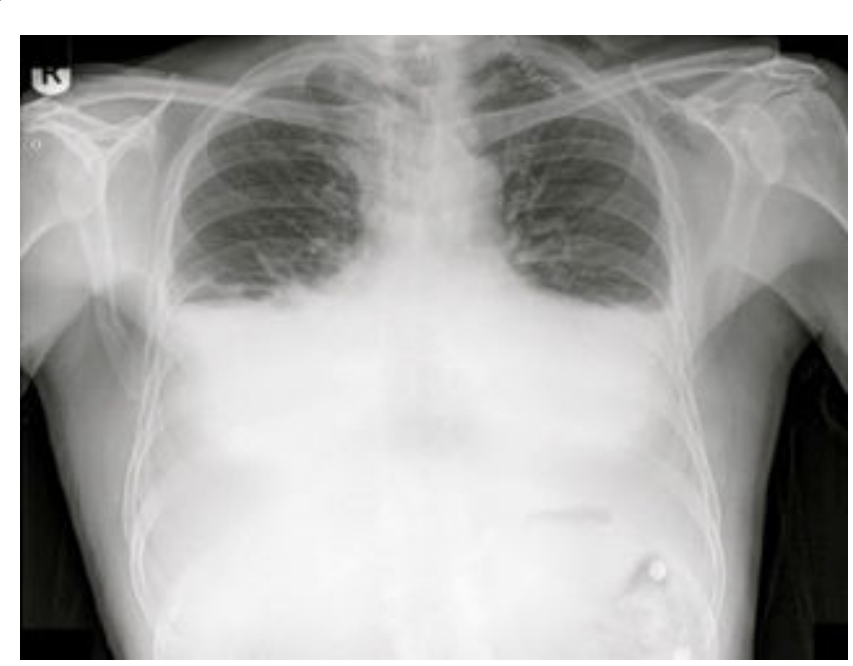

Figure 1: Chest X-ray on $6^{\text {th }}$ post-operative day revealed substantial bilateral pleural effusion with no evidence of pneumothorax.

\section{Anatomy of the thoracic duct}

The average diameter of the thoracic duct in the neck is $2.5 \mathrm{~mm}$. The thoracic duct commences at the level of the second lumbar vertebrae and ascends to the root of the neck with an average length of 380-450 $\mathrm{mm}$. In the neck the duct passes posteriorly to the left carotid sheath before entering the venous system at the junction of the subclavian and internal jugular veins [3]. This is not constant and the thoracic duct may open into anyone of the great veins or divide into a series of tributaries, which leads to a predisposition to injury during left sided neck dissection.

\section{Pathophysiology of chylothorax}

The underlying pathophysiology of a chylothorax is poorly understood with 2 mechanisms postulated [1].

Iatrogenic: Following ligation of the thoracic duct increased intraluminal pressure coupled with negative intra-thoracic pressure 
Page 2 of 2

during inspiration can cause atraumatic extravasation of chyle into the mediastinum.

Obstructive: external compression by a post-operative hematoma or other fluid collections in the neck.

\section{Clinical presentation and diagnosis of chylothorax}

The most common presentation of a post-operative chylous leak, is the presence of a chyle in the suction drain. Chylothorax, however, presents with a sudden onset of dyspnoea coupled with pleural effusions evident on chest radiograph. This can compress structures within the thorax leading to cardiorespiratory compromise. Pleural aspiration is advised as samples obtained can be sent for biochemical and microbiological assessment. The use of Sudan-3 staining and lipoprotein electrophoresis of an aspirate can have high diagnostic yield $[4,5]$.

\section{Management of chylothorax}

A chylothorax if left untreated can lead to cardiorespiratory compromise and a chest drain may be indicated to relieve symptoms. Further surgical intervention is indicated in cases where there is greater than 1 litre drainage daily for 7 days or persistence of more than two weeks chylous fistula, refractory to conservative means with severe metabolic or nutritional complications [1]. Initial surgical intervention includes neck exploration, oversewing of tissue in level 4 and/or the use of tissue sealants. If no leak is identified then intra thoracic, duct ligation either open or endoscopically should be considered. At this stage fibrin glue can be injected into the pleural cavity [1].

In conjunction with surgical management it is imperative, that the patient is closely monitored with daily bloods guiding fluid and electrolyte replacement. An enteral diet rich in medium chain triglycerides is also required. Somatostatin analogues have a suppressive effect on chyle formation, reducing extravasation into the pleura, a fundamental component of medical management [5].
Prophylactic antibiotic cover is also recommended, according to local policy.

There are no clear guidelines on the management of chylothorax. A sound knowledge is essential and the authors highlight 5 key learning points for trainees:

\section{Learning points}

- The course of the thoracic duct in the neck is not constant and the surgeon should always be vigilant.

- A chyle leak is a complication of neck dissection.

- Always be suspicious in a post-operative neck dissection patient who is dyspnoeic and has a pleural effusion that a chylothorax may be present.

- Medical management includes regular monitoring of electrolytes and placing the patient on medium chain triglycerides feed.

- Failure to resolve after 2 weeks of medical management or high output leaks (>1 litre per day) should prompt surgical intervention.

\section{References}

1. Zhang H, Dziegielewski PT, Romanovsky A, Seikaly H (2012) Bilateral chylothorax following neck dissection: case report and systematic review of the literature. J Otolaryngol Head Neck Surg 41: E26-30.

2. Brennan PA, Blythe JN, Herd MK, Habib A, Anand R (2012) The contemporary management of chyle leak following cervical thoracic duct damage. Br J Oral Maxillofac Surg 50: 197-201.

3. Gray's Anatomy (2008) The Anatomical Basis of Clinical Practice, (40thedn.), Susan Standring, Livingstone.

4. Srikumar S, Newton JR, Westin TA (2006) Bilateral chylothorax following left-sided radical neck dissection. J Laryngol Otol 120: 705-707.

5. Kamasaki N, Ikeda H, Wang ZL, Narimatsu Y, Inokuchi T (2003) Bilateral chylothorax following radical neck dissection. Int $\mathrm{J}$ Oral Maxillofac Surg 32: 91-93. 